\title{
LITERATURE STUDY ON HYDRAULIC MODELLING OF FLOODPLAIN MAPPING
}

\author{
F.A.Maniyar ${ }^{1}$, J.P.Bhatt ${ }^{2}$ \\ ${ }^{I}$ M.E.[Water Resource Engineering \& Management] Scholars, Department of Civil Engineering, Shantilal Shah \\ Engineering College, Bhavnagar, Gujarat, India \\ forammaniyar45@gmail.com \\ ${ }^{2}$ Assistant Professor, Department of Civil Engineering, Shantilal Shah Engineering College, Bhavnagar, Gujarat, \\ India.jahnvibhatt@gmail.com
}

\begin{abstract}
As there have been hazardous climatic environments due to climate variation and as a consequence, the intensity of rainfall has increased tremendously causing floods in India. Floods are the most critical among all the natural calamities in world causing vast damages to life and property. It is therefore essential to address these natural calamities by developing integrated approach for the flood modelling and flood mapping for future prevention of flood and to decrease the influence on societies and life and the surroundings. For hydraulic modelling and floodplain mapping was integrated to perform flood routing for the computation of flow peak attenuation, and to perform mapping for the estimation of flood zone depth and the flooded area of reach.The present study focus on various past research works carried out for flood plain and flood inundation mapping. The present study also focus on various hydraulic modelling software and usefulness of Geographic Information System as a tool on the field of water resources engineering and management.
\end{abstract}

Keywords: -Flood, Geographic Information System, Hydraulic Modelling, Inundation, Floodplain Mapping

\section{INTRODUCTION}

Now a days in many emerging countries, natural calamities, such as hurricanes, floods, earthquakes, drought, volcanic eruptions etc. are repeated events. All this natural calamities are inter-connected with environmental characteristics like precipitation and its intensity, temperature, pressure variation, wind velocities, etc. with catchment characteristics like slope, soil type, vegetation, etc. Thus, an imaginary cyclic structure in the form of "Disaster Cycle" appears in one's mind and disaster becomes calamity when it affects lives and properties.

Flooding is the most common natural hazard that can happen any time in wide variety of locations due to high intensity rainfall events, hurricanes, tidal waves, thunderstorms and melting ice or snow. The predictions of climate change trends indicate increase of the occurrence of the intense rainfall events, both in terms of their intensity as well as frequency. Such high intensity rainfall events along with the changes in the land use patterns are expected to have inferences on the intensity of river flooding and local flash flooding in a flood plain region and can substantially alter the spatial extent of future flood. The geographic and demographical development of urban regions can potentially alter the degree of vulnerability in terms of exposure to inundation depths and spatial extent of flood water. Such events encompass multi use reservoirs and retarding structures which accumulate flood waters, canal developments which rises the floods carrying capacity of the river, ridges and banks which keep the water away from floods prone areas, confinement basins which hold up and absorb certain flood water, flood-ways which turn away the flood flows from one waterways to another waterways and create overall development in the drainage structure.

For curtailing the damages due to floods, various flood control methods or devices are adopted. The flood control techniques- which should more properly be termed as "Flood Management" can be scheduled either through structural engineering agencies or non - structural agencies. The justifiable and operational management of flood risk mitigation measures demands a universal approach that can integrate the flood risk calculation information in the decision making process in any proposed developmental activity.

\section{Tools for Modelling}

This paper represents the literature review on application of GIS (Geographical Information System) and HEC-RAS(The Hydrologic Engineering Center's River Analysis System) software's for flood modelling and flood mapping.

[1]. The Geographic talk about to anything that communicates to the arrangement or location of objects in space. It indicates attentiveness in the locational identity of any object on, under or above the earth surface. The information is facts ensuing from the processing or purifying of raw information. A GIS is thus assembly of computer based hardware, software, geologically referenced information, 
techniques and human were organized to handle all form of three-dimensional and non-spatial data to achieve the geographic information needs of a customer.

[2]. The main benefit of using GIS for flood management is that, it does not only produce a picturing of flooding but also generates a potential to further analysis the approximation of apparent damage due to flood. GIS enables assimilation of three-dimensional and nonspatial topographical information such as rainfall and tributary movements, river cross-sections and river basin features. Other data such as flood maps, infrastructures, land-use and socio-economic facts can be inventoried for upcoming use. Flood charts organised by using satellite pictures of actual flood actions and information from the ground are useful for flood loss calculation, forthcoming flood modification planning and justification of hydrologic and hydraulic investigation. It is assumed that these progresses will off era more effective and more precise alternatives to old-fashioned methods for studying watersheds. Therefore GIS united with a hydraulic model has become a handy tool to run a simulation and to understand result in a 3-Dsituation.

[3]. HEC - RAS is one of the most whispered or integrated system of software for computations of 1-D water surface outlines, stable state, gradually varied flow investigation, sediment carrying/mobile bed working out and water temperature modelling and is planned for communicating the multi- tasking multi-user network surroundings comprised of Graphical User Interface (GUI), detached hydraulic study components, information storing and managing abilities and broad casting services. HEC-RAS (Hydrologic Engineering Center River Analysis System) was developed by U.S. Army corps of engineers in 1995 which is a part of the institute for water resource (IWRS). The software is freely available for download at www.hec.usace.army.mil. For unstable flow, HECRAS solves the full, vigorous 1-D flow using saint Venant equation by implicit, finite difference technique. The unstable flow equation solver was reformed from Dr. Robert L. Barkau's UNET package.

The HEC-RAS system comprises four one-dimensional river examination components for: (1) stable flow water surface outline computations; (2) unstable flow simulation; (3) detachable boundary sediment carrying calculation; and (4) water quality investigation. An important element was that all four modules use a mutual geometric data representation and mutual geometric and hydraulic working out procedures. In addition to the four river examination components, the structure comprises several hydraulic strategy features that can be raised once the basic water surface outlines are work out.

\section{Researchers' Contribution On Flood Plain Mapping:-}

\section{1) Eric Kwabenaforkuo}

The paper represented by the Eric KwabenaForkuo describes "Flood Hazard Mapping using Aster Image Data with GIS"'on the prerequisite of an well-organized and profitable methodology for formulating flood vulnerability charts in Ghana, especially in individuals region which are suspected by the flood. By the amalgamation of GIS and ASTER imaginings in grouping of DEM's in describing flood vulnerability level in each district of study area. An additive model was used in combination with the above model in order to generate a composite flood hazard index. In developing this model various parameters were examined such as resident's density, number of settlements in each district, area of civilized ground. Moreover, extreme flood prone zones were also plotted using high resolution DEM and the areas were taken out by applying spatial study on GIS model.

The result acquired in this study will be helpful to the planners and organisation to assess and manage flood vulnerabilities event, and corrective approach. One thematic map area could have been factored into flood vulnerability modelling was the straight forwardness of clearing of life and assets in the occurrence of flood. The study also determines the potential of using GIS application in flood hazard mapping of flood prone areas.

\section{COLLINSFOSU ET AL.}

This paper represented by Collins Fosu et al. aims of river modelling and vulnerability mapping - A case study of Susan River, Kumasi using GIS combined with land model and remotely known information was dynamic in geospatial study of the hydrological phase counting watershed and flood plain allocation.

Methodology:-

In this paper, DEM was involved for any actual flood modelling which was obtained from contour data. The geometric information was taken out from DEM, topographic chart and ground dimensions. All this data were exported to HEC-RAS and GIS software and shows a picture of stage discharge due to flood actions. By the help of remotely sensed image a terrestrial cover plan of the catchment was generated and with the help of land cover map it will outline infrastructural and other damage estimation.

The hazard map produced will delineate three-dimensional scattering of the inundated zone which was situated at areas with low relief. The total flood area cover approximate 2.93 kms and flood depth of 4.01637 was found as the extreme water level. Therefore it is more judicious to model flood plain and low lying zones for both emergency controlling and development scheduling.

\subsection{Chidinma Blessing Okoye Et Al.}

The paper represented by Chidinma Blessing Okoye et al. describes mapping of flood prone zones in Surulere region 
of lagos in Nigeria. The researchers were interested in recognizing the issues that lead to flooding and with the help of GIS software it will chart the flood prone zones in Surulers. The factors that affect the flooding in Surulers were high precipitation concentration; terrestrial use patterns, human act, urban expansion etc. were recognized. The pattern in Surulere region was studied by means of 20 years rainfall data in order to have accuracy in result. The land cover/ land use map and DEM were generated in the ArcGIS and it will clearly define the flood prone zones in the charts.

With the help of map the result was concluded that majority of the terrestrial area were disposed to flooding. Therefore it was important for the Lagos government to implement the necessary methods, awareness and research in order to mitigate flood in Surulers region.

\subsection{Elenikaragiozi Et Al.}

The paper represented by EleniKaragiozi et al. presents the paper on "Flood Hazard Assessment based on Geomorphological Analysis with GIS tools - The Case of Laconia (Peloponnesus, Greece)"targets on the improvement of GIS techniques, to be abused eventually in the form of WebGIS, as a decision backing device for flood vulnerability calculation.

\section{Methodology:-}

In this paper, the flood risk valuation was executed using hydrological models into GIS software considering geomorphologic of the study range. DEM was used as input data for model to generate the hydrograph and the hydrological basins layer. Considering each and every basin morphologic characteristic augmenting flood vulnerability was generated and united in a product in order to generate inherent flood vulnerability chart for every basin. The ultimate flood plan was formed by the integration of the above-mentioned plan and also the slope chart of the study area was formed. The result from following methodology was calculated by means of noted flood events of the study part and revealed that $60 \%$ of the cases were correlated with the established high flood hazard zones, which can be assumed very high.

Eventually, the probability of the device in terms of extra data interface with the static flood risk chart offers the ability to the experts to review the flood vulnerability presenting actual time or nearby time rainfall data when accessible and spatial scattering of rainfall to provide vigorous hazard and risk plans, founded on assumed rainfall actions.

\section{Researchers' Contribution On Application Of}

Hydraulic Modelling Softwares In Water Resources

\section{Engineering And Management:-}

\section{1) Sagargawade Et Al.}

Paper presented by SagarGawadeet al describes Flood
Mapping of Yamuna River, Delhi, India. The change in climatic conditions results into the tremendous increases in the intensity of rainfall which causes flood. To overcome this problem the researcher aims to do river modelling and flood hazard mapping using spatial technology, HEC-RAS hydraulic modelling. In this paper the DEM (digital elevation model) was used for flood modelling process. The geometric data were taken out from the DEM and then a remotely sensed picture was classified into various terrestrial uses which then used for approximating the unevenness co-efficient of various cover types.

The paper expresses the simulated water discharge against observed one water discharge on 23 September 2010 in Yamuna River. The model was established using HEC-RAS, Remote sensing (RS), and geographical information system (GIS)software; so that the flooded zone can be put over on the topographic plan so that it can easily identify the affected area. The vulnerability chart produces will clearly define the three-dimensional distribution of the flooded area which was situated at zones with comparatively lower relief and the total flooded area covers was $15.63 \mathrm{~km}^{2}$ approximately. The researchers also find out the flood depth and velocity in Yamuna floodplain which was obtained as a maximum water level.

The conclusion derived by the researcher was that when GIS was combined with topography model and remotely sensed information which was dynamic in geospatial study of hydraulic modelling of Yamuna river including flood plain delineation and flood mapping. By combination of GIS tools and standard hydraulic modelling the water depth, velocity maps can also be prepared and the flood inundated area can be easily calculated in GIS software for Yamuna River.

\section{2) Goodell C. and Warren C.}

The paper express by Goodell C. and Warren C. describes the flood inundation mapping using HEC-RAS software for the Cameron Run watershed which was located in eastern Fairfax country, in the commonwealth of Virginia, USA. HEC-RAS software is considered as an essential tool for urban and municipal development purpose, emergency action strategies, flood protection taxes and environmental studies. Generally plottinga floodplain prerequisite is topredict the behaviour of the streams, channels, rivers for numerous interval rain storm actions and has capability to transform the predicted data outcome into a strategy assessment of magnitude of inundation.

The main objective of the researchers in their paper was to procedure HEC-RAS software in order to generate flood inundation map and velocity sketches for all of the main tributaries in the Cameron Run Watershed. The researchers consider the current and upcoming conditions for modelling the $1,2,10,25$ and 100 year return interval rainstorms.

In this paper Researchers do the Comparisons of 1 year flood with the 100 year flood. The results were presented in the Arc View shape file polygons and lines in the stable flow version of HEC-RAS. As HEC-RAS software isunique 
model so it will compute and express the water surface elevation for each cross-section and outcomes will not vary large enough along the channel reach cross-section, the overbanks and the corecanal.

The Researchers had conclude that by using HEC-RAS model was, the result obtained will come out prior than in actual and the water surface height in the banks will be slightly lower than in actuality. But these outcomes were valid and accepted in use of planning and designing watershed level study using capabilities of HEC-RAS, ArcGIS and HEC-GeoRAS software.

\section{USMAN KHALIL AND NOOR MUHAMMAD KHAN}

The paper represented by the Usman Khalil and Noor Muhammad Khan describes the Assessment of flood using Geospatial techniques for the Indus River Reach: ChashmaTaunsa.

In this paper researcher had done research on the Indus river reach Chashma-Taunsa for flood modelling and flood mapping for normal flood of 2006 and exceptionally high flood occurred in year 2010. To implement hydraulic modelling and flood plain mapping HEC-RAS, ARC-GIS and its extension Hec-GeoRAS were used for the working out the peak flow attenuation, assessment of lag time between inflow and outflow and to implement mapping for the estimation of flood zone depth and flooded area of reach.

\section{Methodology:-}

In HEC-RAS model input cross-section data were collected from physical survey and extracted from DEM SRTM 90m using Hec-GeoRAS model. The simulated and computed hydrographs upstream of Taunsa Barrage statistical comparison shows the acceptable outcomes i.e. coefficient of determination $\left(\mathrm{R}^{2}\right)$ and Nash and Sutcliffe coefficient as $0.90 \& 0.86$ for year 2006 flood and $0.95 \& 0.93$ for year 2010 flood, which shows good based for the generation of flood inundation in channels. The Researcher had also done comparison of lag times and peak flow attenuation for observed and computed flood peaks of year 2006 and 2010 which show almost good outcome with the observed values. The outcome of HEC-RAS model was exported in Arc-GIS to perform flood mapping.

The conclusion by the researcher was that the flood area computed in model shows good match with the satellite observed data, which shows that the computed flood extents are reliable and will also access the areas vulnerable to flood with estimation of depth for year 2010 flood.

\section{DARSHANJ.MEHTA ET AL.}

The paper represented by the Darshan J. Mehta et al had studied the flood occurring event which was frequently faced by Surat city by releasing the water from the Ukai dam and due to this flood event in river Tapi the Surat city and surrounding regions are badly affected.
The researchers studies stability of a segment of lower reach approximately $6 \mathrm{Km}$ length between weir and Sardar bridge which was calculated for its carrying capacity and stability in response to discharge and slopes using HEC-RAS model for past flood events. As the study area is highly affected by flood and therefore it's necessary to build flood reduction plan for the study area which helps to control big disaster in future.

Moreover the slope of river increases, the velocity of water also rises and hence discharge carrying capacity of river eventually increases. To overcome this problem HEC-RAS model is employed to evaluated flood conveyance performance and also recommended to improve the carrying capacity of Tapi River, so that it will minimize the flood surrounding the Surat city.

The conclusion was derived on the basis of study the sections which are liable to water which overtops the existing embankments or retaining wall required to be raised by construction and also suggested for installation of flood gates on all the storms drain outlets which are without flood gates.

\section{ERIC C.TATE ET AL.}

The paper represented by the Eric et al. which describes on Creating a Terrain Model for Floodplain Mapping.

The paper expresses the use of a geographic information system (GIS) method accessible for the growth of a topography model based on tributary channel depiction of the HEC-RAS model. The researcher has an idea for developing an automated terrain modelling approach in which a technique combine a topography model from HECRAS cross section files and DEM.

\section{Methodology:-}

The process arises with the transfer of the channel information from HEC-RAS to GIS software which was tailed by data alteration from hydraulic model coordinates to topographical coordinates. In order to plot the cross section approach in the study assumes that entirely cross section occurs in straight line so that accurateness of the resultant topography model varies distance from the tributary channel. As the distance along the cross section from the channel increases then there are chances of inaccurately plotting of the cross section. This is particularly true for cross section adjoining the turns in the stream, where investigation plan show a curvature. However, these studies were incapable to obtain precise topography information for zones repeatedly flooded by water and typically accompanied with terrestrial surveys. Therefore, the approach was to assimilate the DEMs with present surveyed tributary data which results into the saving of time and assets.

The conclusion was that the resulting topography DTM precisely describes both channel morphology and floodplain mapping at a vast scale which was required for hydraulic modelling and for the topography model it was produces by 
integrated hydraulic modelling with DTM approach signifies the overall background and it was similar in quality to topography model information acquired through aerial photogrammetry.

\section{CONCLUSION}

From the study of various literatures related floodplain mapping and application of HEC-RAS and Arc-GIS it was concluded that with the help of using this software the flood inundation and flood mapping of the low relief area effected by flood can be easily trace out in order it provides greater response to several return interval storm actions and has capability to transform the predicted data result into a strategy opinion magnitude of submerging. Application of HEC-RAS software is considered as an essential tool for urban and municipal growth purpose, emergency action strategies, flood protection charges and natural studies. The model is consider as useful tool when combine with the GIS tools, determines the water depth, velocity maps can be prepared and the flood inundated area can be easily calculated in GIS software. The HEC-RAS software is useful to study upcoming dangerous conditions by taking the benefit of the physical characteristics by separate modelling approaches and the availability of numerous information, records, data etc.

\section{REFERENCES}

[1]. SagarGawade, KalpanaPardeshi, Dr. R. N. Sankhua "FLOOD MAPPING OF YAMUNA RIVER, DELHI, INDIA" Global Journal Of Multidisciplinary Studies, June- 2015, volume-4(7), Pg.62- 69.

[2]. Eric C. Tate, David R. Maidment, Francisco Olivera and david J. Anderson "CREATING A TERRAIN MODEL FOR FLOODPLAIN MAPPING” Journal of Hydrologic Engineering-ASCE, volume 7(02), 2002, Pg.100-108.

[3]. Darshan J. Mehta, Mr.ManthanRamani and Mr.Maulik Joshi "APPLICATION OF 1-D HEC-RAS MODEL IN DESIGN OF CHANNELS" International Journal of Innovative Research in Advanced Engineering, Volume.1 (07), August-2014, Pg.103-107.

[4]. Goodell.C and Warren.C "FLOOD INUNDATION MAPPING USING HEC-RAS" Obras Y Proyectos, winter 2006, Pg.18-23.

[5]. Usman Khalil and Noor Muhammad Khan “ ASSESSMENT OF FLOOD USING GEOSPATIAL TECHNIQUE FOR INDUS RIVER REACH: CHASHMA-TAUNSA" Science International Journal(Lahore), Volume 27(03),Pg. 1985-1991, 2015.

[6]. Collins Fosu, Eric K. Forkuo and Mensa Y. Asare “ RIVER INUNDATION AND HAZARD MAPPING A CASE STUDY OF SUSAN RIVER" Journal of Global Geospatial Conference, Quebec City, Canada, 2012.

[7]. Eric K WabenaForkuo "FLOOD HAZARD MAPPING USING ASTER IMAGE DATA WITH GIS" International Journal of Geo-matics and Geosciences, Volume1(04), Pg.932-950,2011.

[8]. Chidinma Blessing Okoye and Vincent NdukaOjeh
"MAPPING OF FLOOD PRONE AREAS IN SURULERE, LAGOS, NIGERIA: A GIS APPROACH" Journal of Geographic Information System, volume 7,Pg. 158-176, 2015.

\section{ACKNOWLEDGMENT}

I express a deep sense of gratitude to my guide and motivator Prof. J.P.Bhatt, Assistant Professor, Civil Engineering Department, Shantilal Shah College of Engineering, Bhavnagar, and Gujarat. During the course of this work the constant help, guidance, valuable support, cooperation and giving efforts by her in the right direction without which this work would not have attained the present form. 